\title{
Simplified Prediction Method of Vertical Temperature Distribution for Impinging Jet Ventilation System
}

\author{
Tomohiro Kobayashi ${ }^{1{ }^{*}}$, Toshiya Nishiumi $^{2}$, and Noriko Umemiya ${ }^{2}$ \\ ${ }^{1}$ Graduate School of Engineering, Osaka University, 2-1, Yamadaoka, Suita, Osaka, Japan \\ ${ }^{2}$ Graduate School of Engineering, Osaka City University, 3-3-138, Sugimoto, Sumiyoshi-ku, Osaka, Japan
}

\begin{abstract}
The impinging jet ventilation (IJV) system is an air-distributing strategy to generate a thermal stratification in a room by supplying the air vertically toward the floor, which provides higher ventilation effectiveness than mixing ventilation. To date, however, no simplified prediction model of indoor thermal environment for an impinging jet ventilated room has been established. Therefore, this study aims to propose a simplified calculation model based on "Block Model". This paper first presents a parametric study using Computational Fluid Dynamics (CFD), where total supply airflow rate of a test room is changed as a parameter. The number of terminal is also changed. Secondly, the paper presents the simplified calculation model of vertical temperature distribution based on block model that solves heat flow by advection and diffusion. Here, in this prediction model, the most important parameter is the turbulent thermal diffusivity between two room-space blocks in vertical direction. The room-space blocks are classified into two types, i.e., lower and upper part of a room. Based on parametric study using CFD, turbulent thermal diffusivity is arranged for lower and upper block respectively, and it is finally shown that the vertical temperature distribution from block model well agrees with CFD result.
\end{abstract}

\section{Introduction}

The air distribution system inside a room is of great importance because it has a significant impact on the indoor thermal environment. In addition to providing thermal comfort, energy efficiency of air-conditioning system needs to be carefully considered as well. In this viewpoint, the air distribution system for occupied zone has attracted many interests.

The impinging jet ventilation (IJV) system, which is relatively new air distribution system has been attracting increasing attention during these last two decades. In this system, the air is supplied downwards onto the floor and spreads over a room as a layer with its momentum decreasing gradually. It is generally known that the IJV can combine both advantages of the displacement ventilation (DV) and mixing ventilation (MV) due to a medium momentum supply [1]. If compared with DV system, in IJV system, the air reaches a longer distance owing to higher momentum. Therefore, the IJV system is less likely to generate an undesirable horizontal distribution of temperature and contaminant concentration while maintaining the same strength of the DV system such as the thermal stratification and high ventilation performance. In addition, the IJV system has a possibility to be applied as heating system as well.

In recent years, some research papers focusing on the performance of IJV system have been published [2-7]. When applying the IJV system to a practical airconditioning system design, the thermal stratification inside a room becomes one of the major concerns because it affects the thermal comfort and energy efficiency. In IJV system vertical temperature distribution is affected by both supply air momentum and buoyancy (temperature difference), and it is important to predict it in design phase. Unlike DV system, however, there is still no general and simplified calculation model available at present.

The final goal of this study is to establish a new prediction model of vertical temperature/concentration profile in a room with IJV system. In this paper, the authors aim to propose a simplified prediction method based on the "block model" proposed by Togari et al. [8], where room space is virtually divided into several control volumes in vertical direction. In the block model, the turbulent thermal diffusivity $\left(a_{t}\left[\mathrm{~m}^{2} / \mathrm{s}\right]\right)$ between two room space blocks can significantly affect vertical temperature distribution, but there is still no method proposed that gives appropriate value for $a_{t}$ depending on air supply condition. This paper first presents the parametric study of an impinging jet ventilated room, where supply airflow rate and number of supply terminals are varied. In considering block model, room space blocks are classified into two type, i.e., lower and upper block. Correspondingly, two types of $a_{t}\left(a_{t-u p p e r}, a_{t-}\right.$ upper) are introduced. Then the correlation between these two types of diffusivity and dimensionless number regarding room air characteristics is arranged. Finally, accuracy of the proposed block model is verified by comparison with CFD.

\footnotetext{
Corresponding author: kobayashi@arch.eng.osaka-u.ac.jp
} 


\section{Parametric study using CFD}

In IJV system, as mentioned above, indoor temperature profile is affected by both supply airflow momentum and buoyancy even when the rate of heat flow in supply air is the same. In this section, a parametric study using CFD is performed by changing the total supply airflow rate and number of supply terminal.

\subsection{Target Test Room and Calculation Domain}

In the preceding study, the authors conducted both fullscale experiment and CFD simulation of an impinging jet ventilated room, and verified accuracy of CFD simulation [9]. By analysing a room with the same configuration by using CFD, in this paper, a parametric study regarding the supply airflow momentum and buoyancy is performed.

Fig. 1 shows the basic configuration of the target test room of which dimension is $9.0 \mathrm{~m}(\mathrm{~L}) \times 5.0 \mathrm{~m}(\mathrm{~W}) \times 27$ $\mathrm{m}(\mathrm{H})$. In analysing this room by CFD, only a half part of the room was simulated assuming symmetry to decrease computational load. Four exhaust openings are assumed to be located on the ceiling, and number of vertical duct as supply terminal was changed. A heating element whose heat generation rate was $2.0 \mathrm{~kW}$ was located at the centre of the room as a cooling load.

\subsection{Studied Cases and Method}

As a parameter of the study, the number of supply terminals was changed as 1, 2, 4, and 6. Fig. 2 depicts the floor plan of 4 cases where number of the terminals was changed. The supply opening area is the same for all IJV terminals in all cases to obtain the same supply velocity between corner/side-wall terminals. In addition,

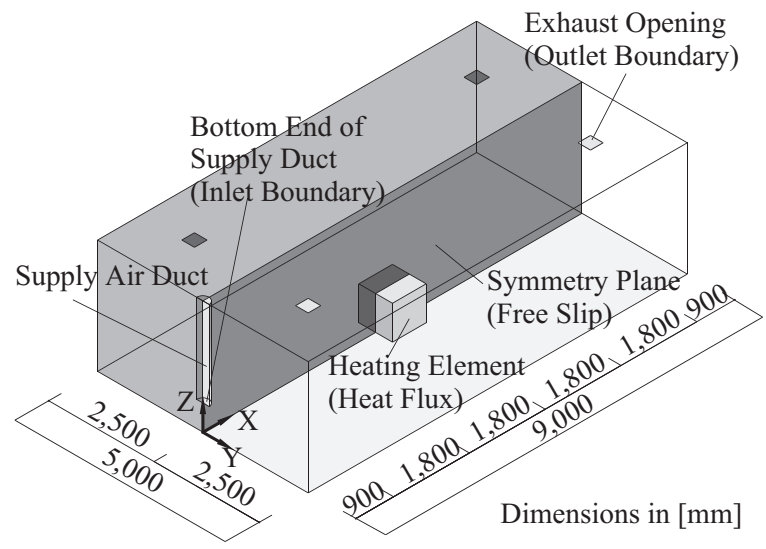

Fig. 1. Computational domain for the target test room.

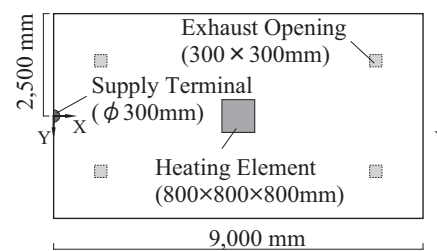

(1) Case 1 (1 Terminal)

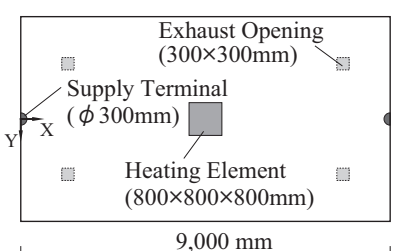

(2) Case 2 (2 Terminals) total supply airflow rate was also changed and three cases of flow rate was studied, i.e., 600, 900, and 1,200 $\mathrm{m}^{3} / \mathrm{h}$. Table 1 summarises the studied cases, and 12 cases were analysed in total. In all cases, supply air temperature was fixed at $20{ }^{\circ} \mathrm{C}$. Here, cases of the same total supply airflow rate condition (e.g., Case 1-1, 2-1, 31 , and 4-1) were intended to enable a comparison under the same condition of supplied heat flow to understand the effect of supply airflow momentum.

According to the accuracy verification in the preceding study [9], the SST k- $\omega$ model was chosen as turbulence model, and steady state calculation was performed with SIMPLE pressure-velocity coupling algorithm. The long-wave radiation heat transfer was also simulated using the surface-to-surface model. Table 2 gives the summary of the method used for CFD analysis.

\subsection{Results and Discussion of Parametric Study}

Fig. 3 shows the vertical distribution of the room temperature obtained from CFD for all cases. Here, each value of temperature is obtained by averaging the spatial

Table 1. All studied cases

\begin{tabular}{c|c|c|c}
\hline Case ID & $\begin{array}{c}\text { Number of } \\
\text { Terminals }\end{array}$ & $\begin{array}{c}\text { Supply Airflow } \\
\text { Rate }\left[\mathrm{m}^{3} / \mathrm{h}\right]\end{array}$ & $\begin{array}{c}\text { Supply Air } \\
\text { Velocity }[\mathrm{m} / \mathrm{s}]\end{array}$ \\
\hline Case 1-1 & 1 & 600 & 4.716 \\
\hline Case 1-2 & 1 & 900 & 7.074 \\
\hline Case 1-3 & 1 & 1,200 & 9.431 \\
\hline Case 2-1 & 2 & 600 & 2.358 \\
\hline Case 2-2 & 2 & 900 & 3.537 \\
\hline Case 2-3 & 2 & 1,200 & 4.716 \\
\hline Case 3-1 & 4 & 600 & 1.179 \\
\hline Case 3-2 & 4 & 900 & 1.768 \\
\hline Case 3-3 & 4 & 1,200 & 2.358 \\
\hline Case 4-1 & 6 & 600 & 0.786 \\
\hline Case 4-2 & 6 & 900 & 1.179 \\
\hline Case 4-3 & 6 & 1,200 & 1.572 \\
\hline
\end{tabular}

Table 2. Summary of CFD calculation setting

\begin{tabular}{|c|c|c|c|c|c|c|}
\hline \multicolumn{2}{|c|}{ CFD code } & \multicolumn{5}{|c|}{ Ansys Fluent 14.5} \\
\hline \multicolumn{2}{|c|}{ Turbulence Model } & \multicolumn{5}{|c|}{ SST k- $\omega$ Model } \\
\hline \multicolumn{2}{|c|}{ Radiation Model } & \multicolumn{5}{|c|}{ Surface-to-surface Model } \\
\hline \multicolumn{2}{|c|}{ Algorithm } & \multicolumn{5}{|c|}{ SIMPLE } \\
\hline \multicolumn{2}{|c|}{$\begin{array}{c}\begin{array}{c}\text { Discretization Scheme } \\
\text { for Advection Term }\end{array} \\
\end{array}$} & \multicolumn{5}{|c|}{ QUICK } \\
\hline \multirow{7}{*}{$\begin{array}{l}\text { Boundary } \\
\text { Conditions }\end{array}$} & \multirow{4}{*}{ Inlet } & & Case 1-1 & Case 2-1 & Case 3-1 & Case 4-1 \\
\hline & & $V[\mathrm{~m} / \mathrm{s}]$ & 4.716 & 2.358 & 1.179 & 0.786 \\
\hline & & $I[\%]$ & 10 & 10 & 10 & 10 \\
\hline & & $L[\mathrm{~mm}]$ & 21 & 21 & 30 & 21 \\
\hline & Outlet & \multicolumn{5}{|c|}{ Velocity Magnitude $: 0.463 \mathrm{~m} / \mathrm{s}$} \\
\hline & $\begin{array}{l}\text { Walls } \\
\text { (Heat) }\end{array}$ & \multicolumn{5}{|c|}{$\begin{array}{l}\text { Room Walls : External Temperature } \\
\text { Heating Element Surface : Heat Flux }\end{array}$} \\
\hline & $\begin{array}{c}\text { Walls } \\
\text { (Velocity) }\end{array}$ & \multicolumn{5}{|c|}{ Symmetry : Free Slip } \\
\hline \multicolumn{2}{|c|}{ Total Number of Cells } & $\begin{array}{r}\text { Case } 1 \\
2,625,15\end{array}$ & $\begin{array}{rr} & \text { Cas } \\
4 & 2,936\end{array}$ & $\begin{array}{rr}2 & \mathrm{Ca} \\
478 & 3,63\end{array}$ & $\begin{array}{l}\text { ase } 3 \\
32,340\end{array}$ & $\begin{array}{c}\text { Case } 4 \\
3,887,170\end{array}$ \\
\hline
\end{tabular}

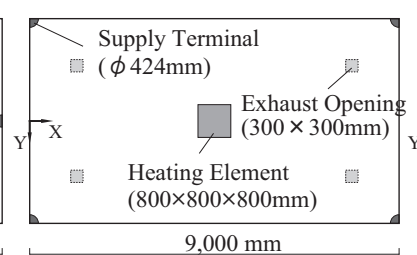

(3) Case 3 (4 Terminals)

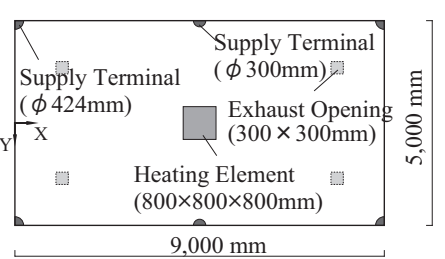

(4) Case 4 (6 Terminals)

Fig. 2. Studied Cases (number of supply terminals) 


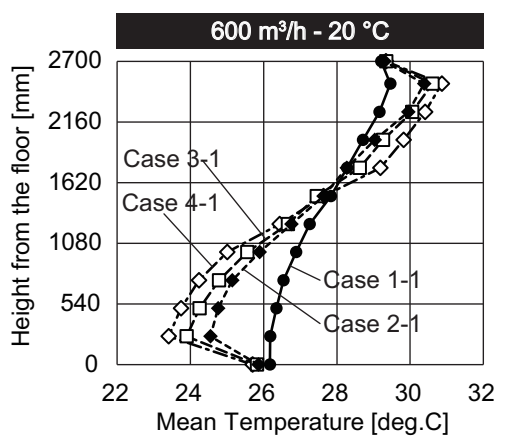

(1) Airflow Rate : $600 \mathrm{~m}^{3} / \mathrm{h}$

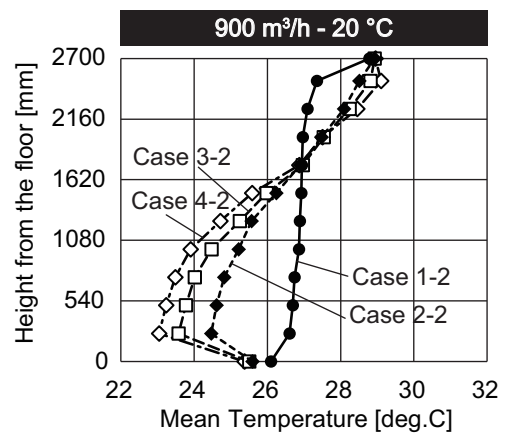

(2) Airflow Rate : $600 \mathrm{~m}^{3} / \mathrm{h}$

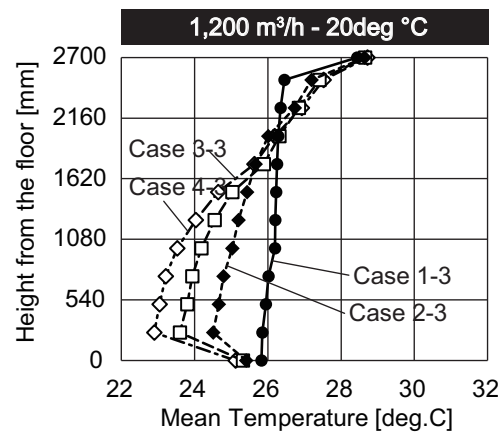

(3) Airflow Rate : $600 \mathrm{~m}^{3} / \mathrm{h}$

Fig. 3. Vertical profiles of Temperature averaged over the horizontal cross-section for all cases

temperature over the horizontal cross-section of the room. As a general tendency, the temperature gradient in vertical direction becomes larger as the number of supply terminal increases even when total supply airflow rate is the same. This is obviously due to low momentum of the supplied airflow. Focusing on the cases of 900 and $1,200 \mathrm{~m}^{3} / \mathrm{h}$ of supply airflow rate (Fig.3 (2) and (3)), only the cases where one supply terminal was provided shows almost uniform temperature distribution (Case 1-2, 1-3), where supplied airflow velocity is approximately 7.1 and $9.4 \mathrm{~m} / \mathrm{s}$. According to each of these three diagrams, it was shown that the temperature distribution significantly differs even when the total supply airflow rate and supply air temperature are fixed, and this difference in temperature profile was obviously caused by difference in supply airflow momentum. This can also be interpreted that the airflow behaviour of turbulent diffusion strongly affects temperature distribution. In designing air-conditioning system using IJV system, it is important to predict such a vertical profile in the design phase, but there is still no simplified prediction method which is practically available. Therefore, in the following section, the authors propose a calculation model based on block model, which can consider difference in supply airflow momentum.

\section{Prediction using simplified Model}

\subsection{Outline of the Calculation Model}

As mentioned above, the block model proposed in this study is basically based on that by Togari et al [8], which intends to predict vertical temperature profile of a room where almost uniform distribution is generated horizontally. In this model, a room is divided into several blocks in vertical direction, and three types of block are assumed in this study, i.e., room space block, wall surface current block, and plume block. The mass conservation and heat flow balance considering both advection and diffusion are solved among blocks as control volumes. The configuration of the analysed room was assumed to be the same as the previous section. The indoor space was divided into 10 blocks for room space block, plume block, and wall surface current block respectively, i.e., 30 blocks in total. The schematic of the calculation model is illustrated in Fig.4.

In the previous chapter, height of the bottom end of supply terminal was $600 \mathrm{~mm}$ from the floor, but in this model calculation, all mass flow of supplied air is input into the bottom room space block (block 10) because supplied airflow impinges on the floor in IJV system. Heat generation from the heating element is also input

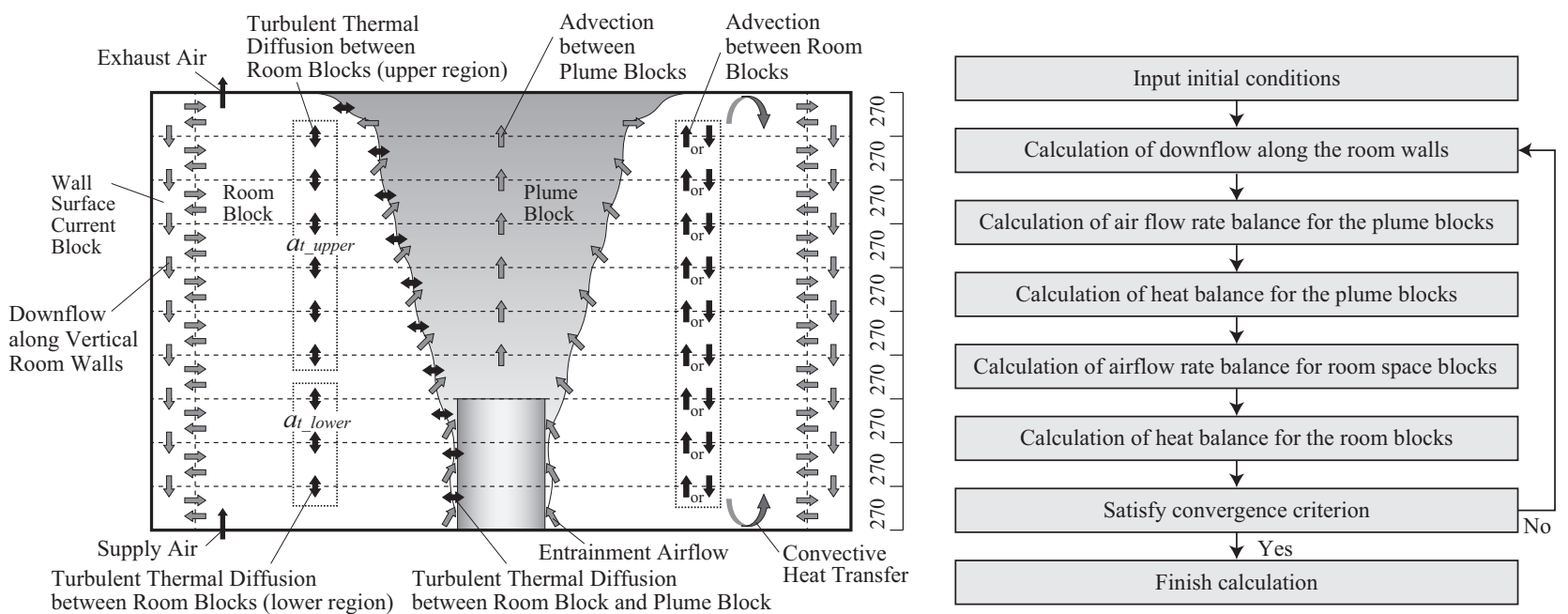

Fig. 4. Schematic of the Block Model for IJV System and Computational Procedure of Iterative calculation

Fig. 5. Computational Procedure in the Block Model 
into the bottom block, and heat generation rate was set at $2.0 \mathrm{~kW}$ as well as the previous section. The air is assumed to be exhausted from the top room space block (block 1). Supplied air temperature was $20^{\circ} \mathrm{C}$. The wall surface temperature was given as boundary condition, and CFD result was used here. Convective heat transfer at wall surface was considered, where heat transfer coefficient was given by Jürges's empirical equation where velocity was defined by supply airflow rate divided by floor area.

\subsection{Calculation Procedure}

The procedure of iterative calculation in the simplified model is shown in Fig. 5. After inputting initial conditions of temperature, flow rate of the wall surface current and inflow/outflow rate across the boundary of room space block $\left(V_{\text {in }}, V_{\text {out }}\right)$ are first calculated according to the original model of Togari et al. [8]. Secondly, flow rate of the thermal plume is calculated. Here, the target room is provided with a heating element with relatively large generation rate, and strong thermal plume affecting indoor environment can be generated. Here, the flow rate of the plume is calculated by using following equation of point source.

$$
V_{P}=0.005 \times W^{\frac{1}{3}} \times\left(h-h_{0}\right)^{\frac{5}{3}}
$$

where, $W$ is heat generation rate, $h$ is height from the floor, and $h_{0}$ is the height of virtual point source. Based on the plume flow rate, entrained flow rate from the room space block can be obtained and mass conservation (airflow rate balance) for plume block can be solved. Then, mass conservation for room space block are solved as well. Based on calculated flow rate and tentative temperature, heat flow balance is solved and temperature is updated. In solving the heat flow balance, turbulent diffusion needs to be considered, because it significantly affects temperature profile, and especially turbulent diffusion in vertical direction is important in this case. In order to evaluate the heat flux by turbulent diffusion, the heat transfer coefficient, $\mathrm{C}_{\mathrm{b}}\left[\mathrm{W} /\left(\mathrm{m}^{2} \cdot \mathrm{K}\right)\right]$, is defined by using turbulent thermal diffusivity, $a_{t}\left[\mathrm{~m}^{2} / \mathrm{s}\right]$, which is here given by following equation,

$$
C_{b}=a_{t} \times C_{p} \rho / H_{b}
$$

where, $a_{t}$ is turbulent thermal diffusivity in vertical direction $\left[\mathrm{m}^{2} / \mathrm{s}\right], C_{P} \rho$ is volumetric specific heat $\left[\mathrm{J} /\left(\mathrm{m}^{3} \cdot \mathrm{K}\right)\right]$, and $H_{b}$ is the block height. Although is seems less important than vertical turbulent diffusion, horizontal diffusive heat flux is also considered between room space and plume blocks by using heat transfer coefficient $C_{b p}$ which is here given by constant value of $1.0\left[\mathrm{~W} /\left(\mathrm{m}^{2} \cdot \mathrm{K}\right)\right]$.

By repeating the calculation procedure illustrated above iteratively, vertical temperature profile can be obtained in this model. Fig. 6 shows the schematic of the heat transfer by advection, diffusion, and convective heat transfer among calculated blocks. The Black arrows in the figure indicate the heat transfer by advection, the grey ones across the boundary between blocks are turbulent diffusion. Table 4 summarises the equations solved in this block model. The mass conservation and heat balance equations within the wall surface current blocks are here omitted because equations in the original model proposed by Togari et al. [8] was used without any change.

As shown in the parametric study in the previous section, indoor vertical temperature distribution can significantly vary depending on supply airflow momentum or total supply airflow rate. This seems to be due to the difference in turbulent diffusion behaviour. In order to reflect this effect in the block model, a rational method to give appropriate value for turbulent thermal diffusivity $a_{t}$ is required. To do this, in the following subsection, turbulent thermal diffusivity that shows best agreement with CFD is determined, which is the major objective of this study.

\section{3. Determination of Turbulent Diffusivity}

This subsection aims to propose a rational method to determine turbulent thermal diffusivity between room space block in vertical direction by using CFD results which is assumed to have sufficient accuracy. Since the turbulent diffusivity, $a_{t}$, is local turbulent statistics, different value should be given for every boundary between two room space blocks. In this model, however, the room space blocks are classified into two types for simplicity, i.e., upper part and lower part of the room. Within the one part of the room (upper part or lower part), the same value of turbulent thermal diffusivity is

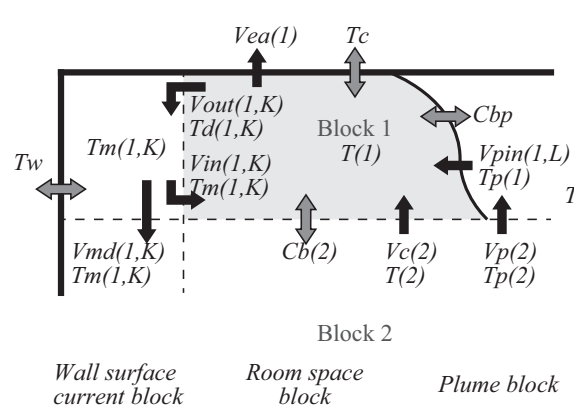

(1) Top Block (Block 1)

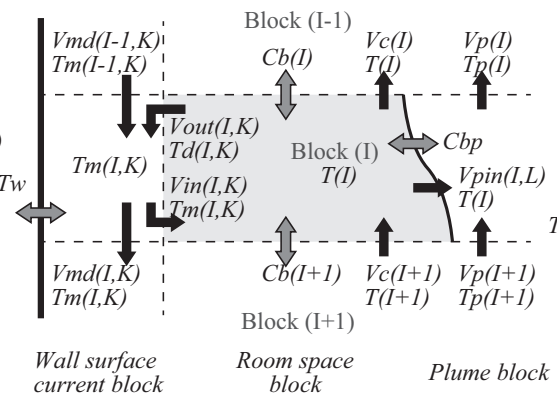

(2) Medium Block (Block 2 9)

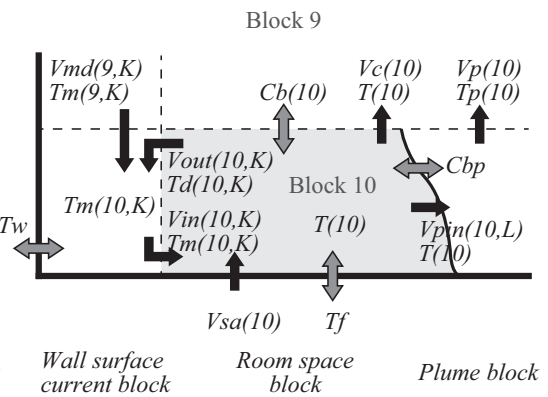

(3) Bottom Block (Block 10)

Fig. 6. Schematic of Heat Transfer among Control Volumes 
Table 3. Mass Conservation and Heat Balance Equations solved in the Block Model for IJV System

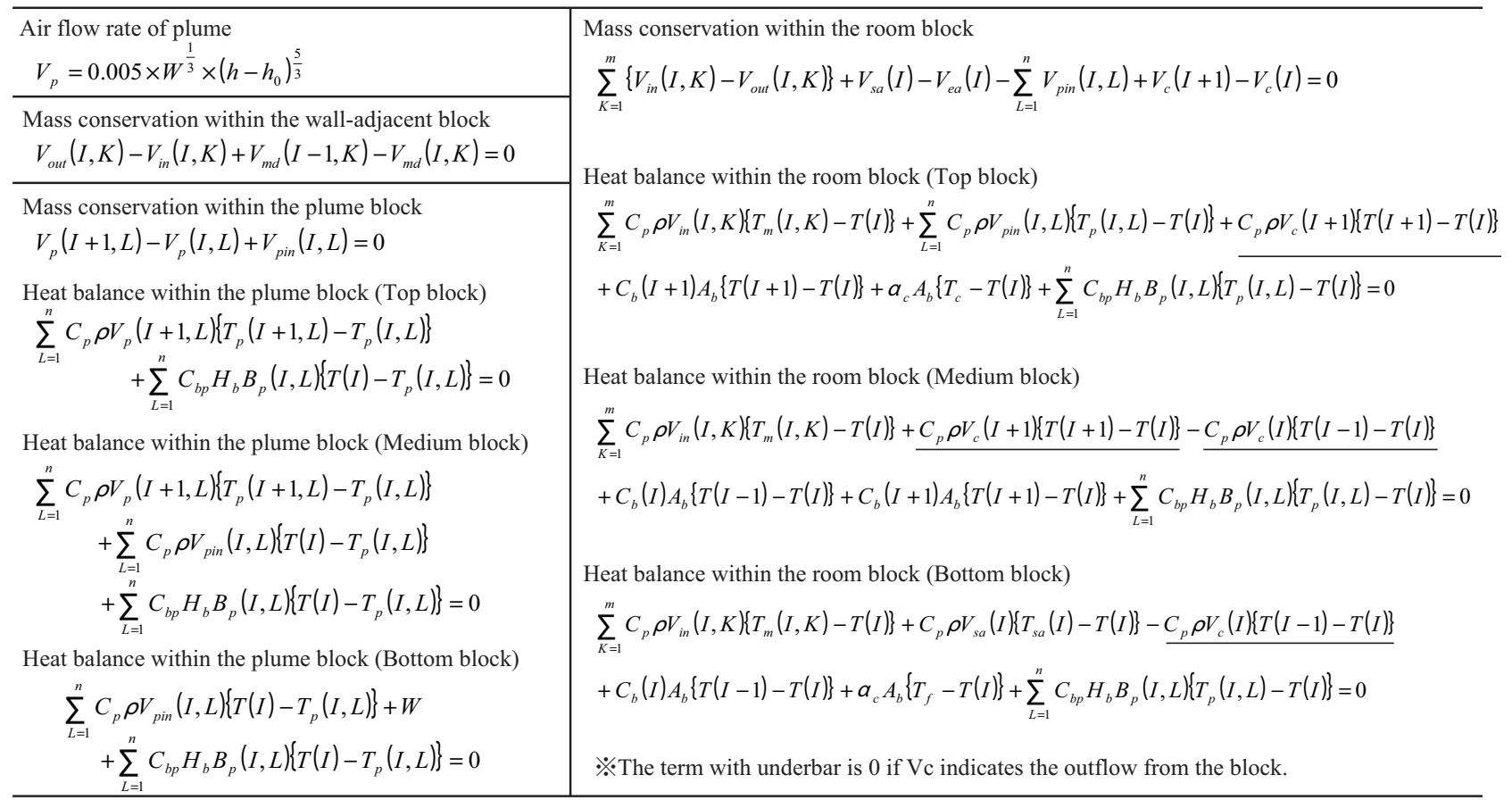

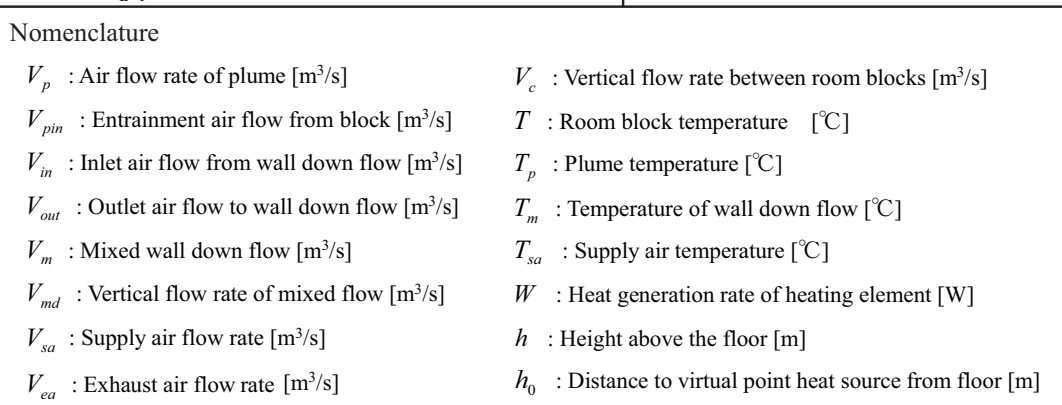

$h_{0}$ : Distance to virtual point heat source from floor [m]

\author{
$B$ : Circumferential length of heating element $[\mathrm{m}]$ \\ $C_{p} \rho:$ Volumetric specific heat of air $\left[\mathrm{J} /\left(\mathrm{m}^{3} \cdot \mathrm{K}\right)\right]$ \\ $A_{b}$ : Area of boundary surface of block $\left[\mathrm{m}^{2}\right]$ \\ $H_{b}$ : Height of one block [m] \\ $B_{p}$ : Circumferential length of plume [m] \\ $C_{b}$ : Heat transfer coefficient between blocks $\left[\mathrm{W} /\left(\mathrm{m}^{2} \cdot \mathrm{K}\right)\right]$ \\ $C_{b p}:$ Heat transfer coefficient around plume $\left[\mathrm{W} /\left(\mathrm{m}^{2} \cdot \mathrm{K}\right)\right]$
}

adopted for all the boundaries, and defined as $a_{t \_u p p e r}$ and $a_{t \_l o w e r}$ for upper part and lower part respectively. The rationale of this assumption considering two parts is that the flow characteristic is different between lower and upper part. Namely, mixing of the air is strongly affected by supplied air jet with relatively high momentum in the lower part of the room, while buoyancy seems to be dominant in the upper part. Regarding CFD results presented in Fig. 3 as true value, a combination of $a_{t \_u p p e r}$ and $a_{t-l o w e r}$ that shows best agreement in temperature profile between CFD and block model is determined for each case by using the least squares method. Here, $a_{t \_ \text {upper }}$ is assumed to be the diffusivity at the horizontal boundaries within the block 1 to 7 , and $a_{t \_l o w e r}$ is that for the block 8 to 10 .

Table 4 gives the obtained turbulent thermal diffusivity that showed the best agreement with CFD for all cases. Since the mixing of air in the room is promoted as inlet momentum increases, as a general tendency, turbulent thermal diffusivity clearly becomes larger as inlet velocity large. Although inlet velocity is dominant in the lower part, it affects mixing characteristics in the upper part of the room as well.

Fig. 7 shows the vertical profiles of horizontalaveraged temperature obtained from CFD and that
Table 4. Turbulent Thermal Diffusivity for Upper and Lower Region of the Room Determined by Least Squares Method

\begin{tabular}{c|c|c}
\cline { 2 - 3 } & $a_{\text {t_upper }\left[\mathrm{m}^{2} / \mathrm{s}\right]}$ & $a_{\text {t_lower }}\left[\mathrm{m}^{2} / \mathrm{s}\right]$ \\
\hline Case 1-1 & 0.011 & 0.018 \\
\hline Case 1-2 & 0.12 & 0.14 \\
\hline Case 1-3 & 0.23 & 0.10 \\
\hline Case 2-1 & 0.0019 & 0.0079 \\
\hline Case 2-2 & 0.0073 & 0.020 \\
\hline Case 2-3 & 0.020 & 0.066 \\
\hline
\end{tabular}

\begin{tabular}{|c|c|c|}
\hline & $a_{t_{-} \text {upper }}\left[\mathrm{m}^{2} / \mathrm{s}\right]$ & $a_{t_{-} \text {lower }}\left[\mathrm{m}^{2} / \mathrm{s}\right]$ \\
\hline Case 3-1 & 0.0011 & 0.0049 \\
\hline Case 3-2 & 0.0028 & 0.010 \\
\hline Case 3-3 & 0.0083 & 0.033 \\
\hline Case 4-1 & 0.00050 & 0.0058 \\
\hline Case 4-2 & 0.0011 & 0.011 \\
\hline Case 4-3 & 0.0035 & 0.021 \\
\hline
\end{tabular}

obtained from block model using determined turbulent diffusivity shown in Table 4. In general, the temperature profile predicted by block model well agrees with CFD for all cases, small discrepancy can be seen in Case 1-4. The good agreement between CFD and the block model seems to be somewhat natural result because the turbulent diffusivity that the best agreement was used. However, it also indicates the validity of the hypothesis that the room can be classified into two parts in the simplified prediction model. The most important issue in using this model is how to estimate appropriate value for turbulent thermal diffusivity, $a_{t \_ \text {upper }}$ and $a_{t_{-} \text {lower }}$. Therefore, in the following subsection, the correlation between these two kinds of turbulent diffusivity and important factor showing the airflow characteristics in the room that can be calculated from the design parameters such as airflow rate, supply air temperature, and so on. 

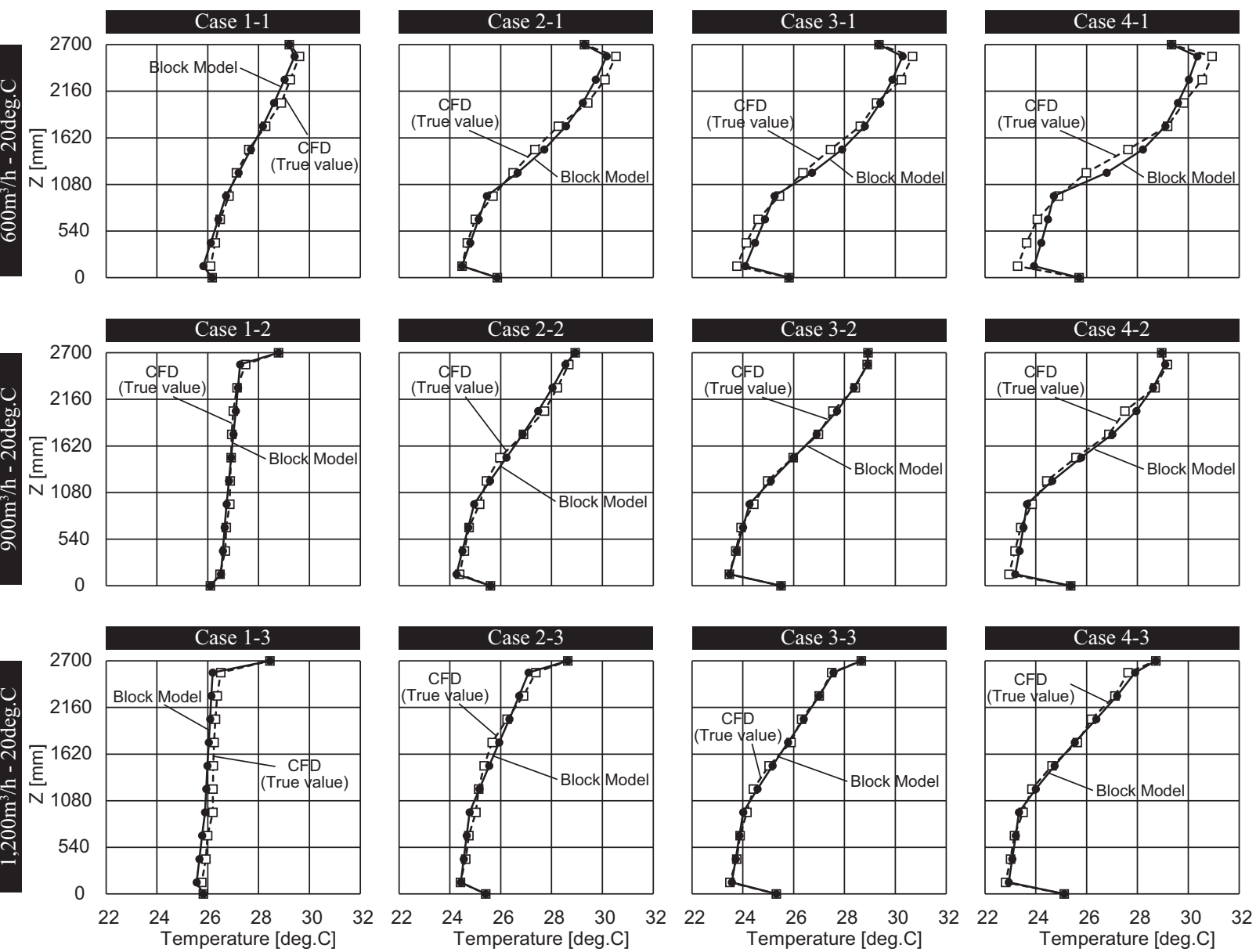

Fig. 7. Vertical Profiles of Horizontal-Mean Room Temperature obtained from CFD and Block Model using Determined Trubulent Thermal Diffusivity

\section{4. Function to obtain Turbulent Diffusivity}

For the sake of establishment of simplified calculation model of vertical temperature distribution, as shown in the previous subsection, appropriate value of two kinds of turbulent thermal diffusivity needs to be predicted. In this viewpoint, it would be beneficial if they could be predicted by using dimensionless number defined by several important design parameters. Here, as a basic investigation, it is assumed that $a_{t_{-} \text {lower }}$ is strongly affected by inlet velocity and temperature difference between supplied air and the bottom block, and $a_{t \_l o w e r}$ is related with vertical temperature difference between top and bottom block. To express these parameters by dimensionless number, two kinds of Archimedes number is here defined as follows.

$$
\begin{aligned}
& A r_{S A}=\frac{g \beta \sqrt{A_{\text {in }}}\left(T_{10}-T_{S A}\right)}{v_{S A}^{2}} \\
& A r_{\text {room }}=\frac{g \beta H_{r}\left(T_{E A}-T_{S A}\right)}{v_{S A}^{2}}
\end{aligned}
$$

where, $g$ is gravitational acceleration $\left[\mathrm{m} / \mathrm{s}^{2}\right], \beta$ is thermal expansion coefficient $[1 / \mathrm{K}]$ which was here given by reciprocal of supply air temperature, $A_{i n}$ is inlet area of the supply terminal $\left[\mathrm{m}^{2}\right], v_{S A}$ is supply air velocity $[\mathrm{m}]$,
$T_{S A}$ is supply air temperature, $T_{E A}$ is exhaust air temperature $\left[{ }^{\circ} \mathrm{C}\right]$, and $\mathrm{Hr}$ is ceiling height $[\mathrm{m}]$. It is assumed that $A r_{S A}$ is applied where effect of the inlet jet is dominant, and $A r_{\text {room }}$ is for upper part of the room where buoyancy inside a room is important.

Fig. 8 shows the correlation between Archimedes number and turbulent thermal diffusivity for each part of the room. Obviously a negative correlation can be seen for both upper and lower parts. Small value of the Archimedes number indicates higher momentum of the supplied air relative to buoyancy, which causes higher mixing of the air. This should be expressed by larger value of turbulent diffusivity. This corresponds to the tendency shown in Fig. 8, and the fitting equations to predict turbulent diffusivity using Archimedes number

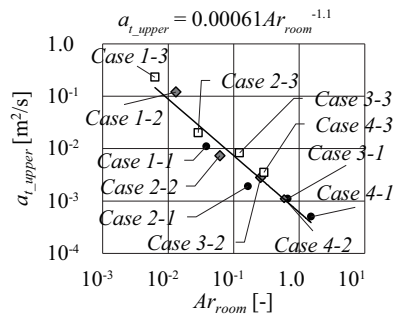

(1) Upper Part

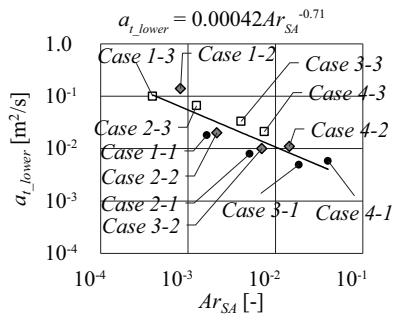

(2) Lower Part
Fig. 8. Correlation between Archimedes Number and Turbulent Thermal Diffusivity for Upper and Lower Region 
seem to be rational and available to some extent in predicting thermal stratification using this block model. The turbulent diffusivity in the lower part, $a_{t \_l o w e r}$, shows larger value even when the Archimedes number is large if compared with $a_{t \text { upper }}$. This can be interpreted to be due to that the air in the lower part is mixed by supplied air that is impinging on the floor. From this result, there is a possibility that the Archimedes number defined in this work can be an important parameter that explains vertical temperature distribution. However, the number of parameter investigated in the numerical study in this paper is still not sufficient, and further study including other conditions of heat load or room configuration seems to be needed in the future work.

\section{Conclusions}

This paper presented the parametric study of a room with IJV system by using CFD where total supply airflow rate and number of inlet terminal were changed, and 12 cases were analysed in total. It was shown that vertical temperature distribution could significantly differ depending on supply airflow momentum even when total airflow rate was the same.

To enable one to easily predict vertical profile of a room with IJV system even in the design phase, the block model based on the preceding study was proposed as a simplified calculation model. Since the turbulent thermal diffusivity has a great impact on vertical temperature profile in the model, the method to give this diffusivity was proposed by classifying the room space into two parts, i.e., upper part and lower part. It was assumed that the turbulent diffusivity at a room space block boundary is uniform within lower part of the room, and upper part as well. Therefore, two kinds of turbulent thermal diffusivity, $a_{t \_l o w e r}$ and $a_{t \_ \text {upper }}$, were defined. Regarding CFD result as true value, the combination of these two kinds of diffusivity that showed best agreement between CFD and block model was determined.

The temperature profile predicted by simplified block model using determined diffusivity well agreed with CFD, but how to give appropriate diffusivity is most important in the model. To propose this, two kinds of Archimedes number, $A r_{S A}$ and $A r_{\text {room }}$ were new proposed, which could be important parameter to explain mixing characteristic and were corresponding to $a_{t \_l o w e r}$ and $a_{t \_ \text {upper }}$ respectively. The correlation between turbulent diffusivity and Archimedes number was arranged for lower and upper part respectively, and clear negative correlation was shown, i.e., large Archimedes number resulted in less mixed air behaviour due to lower inlet momentum. Comparing $a_{t_{-} \text {lower }}$ and $a_{t_{-} \text {upper }}$, the former tended to become large because of supplied jet impinging on the floor. In general, validity of the proposed method to predict thermal stratification of a room with IJV system was shown. However, further study under many conditions of heat load, room configuration seems to be needed.

\section{Acknowledgement}

The help from Mr. Kazuki Sugita (master's course student in Osaka City University when the work was in progress) in conducting CFD simulation and calculation using block model is gratefully acknowledged.

\section{References}

1. T. Karimipanah, H. B. Awbi, Build. Environ., Theoretical and experimental investigation of impinging jet and comparison with wall displacement ventilation, 37, 1329-1342 (2002)

2. J. Varodompun, M. Navvab, Proceedings of IAQVEC 2017, The full scale and CFD simulation of impinging jet ventilation, in Digital Media (2007)

3. H. J. Chen, B. Moshfegh, M. Cehlin, Build. Environ., Numerical investigation of the flow behavior of an isothermal impinging jet in a room, 49, 154-166 (2012)

4. H. J. Chen, B. Moshfegh, M. Cehlin, Build. Environ., Investigation on the flow and thermal behavior of impinging jet ventilation systems in an office with different heat loads, 59, 127-144 (2013)

5. H. J. Chen, B. Moshfegh, M. Cehlin, Build. Environ., Computational investigation on the factors influencing thermal comfort for impinging jet ventilation, 66, 29-41 (2013)

6. X. Ye, H. Zhu, Y. Kang, K. Zhong, Energy Build., Heating energy consumption of impinging jet ventilation an mixing ventilation in large-height spaces : a comparison study, 130, 697-708 (2016)

7. B. Zuo, K. Zhong, Y. Kang, Build. Environ., An experimental study on particle resuspension in a room with impinging jet ventilation, 89, 48-58 (2015)

8. S. Togari, Y. Arai, K. Miura, ASHRAE Trans., $A$ Simplified model for predicting vertical temperature distribution in a large space, 99 (1), 84-99 (1993)

9. T. Kobayashi, K. Sugita, N. Umemiya, T. Kishimoto, M. Sandberg, Build. Environ., Numerical investigation and accuracy study for an impinging jet ventilated room using computational fluid dynamics, 115, 251-268 (2017) 